\section{Kinder mit Asthma besonders anfällig für H1N1-Grippeviren}

Bei einer Infektion mit dem H1N1-Virus, der sogenannten Schweinegrippe, ist Asthma die häufigste Komorbidität, die zu einer Hospitalisierung führt. Die Auswertung der Grippesaison 2009 in den USA von K. M. Kloepfer et al. hat nun gezeigt, dass Kinder mit Asthma weit häufiger von H1N1-Infektionen betroffen waren als von anderen respiratorischen Viren. Am J Respir Crit Care 2012; 185: 1275-1279

Die H1N1-Grippewelle im Frühjahr 2009 in den USA erfasste letztendlich 61 Millionen Menschen, davon ein Drittel Kinder. 87000 Betroffene unterzogen sich einer stationären Behandlung, wobei als häufigste zur Hospitalisierung führende Komorbidität Asthma vorlag. Die Studienautoren überprüften, ob bei jungen Asthma-Patienten die Infektionsrate mit dem Influenzavirus höher und die Schwere der Erkrankung stärker waren, als bei denen ohne Asthma.

Die Wissenschaftler nahmen 180 Kinder im Alter von 4-12 Jahren in ihre Untersuchung auf. Sie sammelten während 8 aufeinanderfolgenden Wochen nasale Schleimproben, bewerteten täglich die Erkältungs- und Asthmasymptome und führten mit jeder Schleimprobe eine virale Diagnostik durch. Bis zum Ende der Untersuchung hatten sie insgesamt 161 vollständige Proben gesammelt; 95(59\%) von Asthmatikern und 66 von Kindern ohne Asthma.

\section{Erhöhte Inzidenz von H1N1-Infektionen $\nabla$}

Die Untersucher beobachteten insgesamt 346 (unterschiedliche) Infektionen bei den 161 Kindern, die diese Studie vollständig mit mindestens 6 von 8 nasalen Proben beendeten. $\mathrm{Zu} 62$ \% lagen Infektionen mit menschlichen Rhinoviren (MRV) vor, $12 \%$ waren Enteroviren und 10\% H1N1-Viren. Bei multiplen Viren in einer Probe bestanden diese zu 80\% aus MRV und zu 51\% aus H1N1. Wie die Auswertung ergab, lag die Inzidenz von H1N1-Infektionen mit $41 \%$ bei Kindern mit Asthma deutlich höher als bei Kindern ohne Asthma mit 24\%. Andererseits waren die Infektionsraten mit Rhinoviren mit $90 \%$ in beiden Gruppen gleich und mit anderen Viren (47 bzw. $41 \%$ ) ähnlich hoch. Bei Kindern mit Asthma bestand kein verstärkter Verlust der Asthmakontrolle während der H1N1-Infektionen im Vergleich zu denen, die nur mit Rhinoviren infiziert waren (38 vs. $21 \%$; $=0,07$ ).

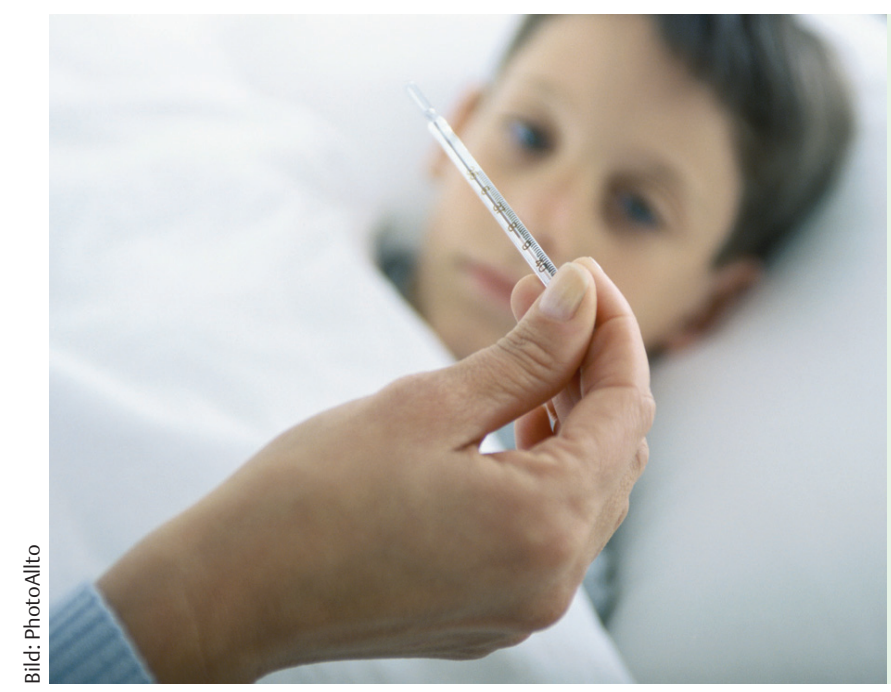

Im Frühjahr 2009 breitete sich ein neuartiger Subtyp des H1N1-Virus zunächst in Nordamerika aus und verursachte bald darauf eine Pandemie. Kinder und Erwachsene zeigten die typischen Grippesymptome wie Fieber, ggf. mit Schüttelfrost, Kopfschmerzen, Myalgien, Pharyngitis und Husten.
Insgesamt lösten H1N1-Infektionen bei diesen Kindern im Vergleich zu anderen viralen Infektionen schwerwiegendere Erkältungssymptome aus.

\section{Fazit}

Kinder mit Asthma waren fast doppelt so häufig mit H1N1 als mit anderen Viren des Respirationstraktes infiziert. Die Befunde werfen neue Fragen über den Mechanismus auf, der dieser erhöhten Anfälligkeit gegenüber Influenzainfektionen bei Asthmatikern zugrunde liegt. Eine Antwort auf diese Fragen könnte nach Ansicht der Autoren zu neuen Ansätzen für die Prävention und Behandlung von Influenza bei Kindern mit Asthma führen.

Dr. Volker Kriegeskorte, Buchloe

Ausschreibung

\section{Wissenschaftspreis des Deutschen Ärztinnenbundes}

Der Deutsche Ärztinnenbund e.V. verleiht 2013 zusammen mit der Dr. EdithGrünheit-Stiftung einen mit $4000 €$ dotierten Wissenschaftspreis, bei dem die Geschlechterdifferenz in Diagnostik, Therapie, Prävention und biomedizinischer Forschung im Mittelpunkt steht. Es werden ausschließlich Arbeiten prämiert, die sich zentral mit dieser Thematik befassen. Prof. Marianne Schrader, Vizepräsidentin des Deutschen Ärztinnenbundes, erläutert: „Der Preis mit diesem speziellen Fokus wird seit 2001 in 2-jährigem Turnus an junge Ärztinnen und Zahnärztinnen aus Klinik und Wissenschaft verliehen, die in ihrer Arbeit die biologischen und/oder soziokulturelle Unterschiede zwischen den Geschlechtern mit Relevanz zur medizinischen Versorgung in Design und Auswertung im Fokus haben.“

Bewerbungen mit Lebenslauf und Publikationsliste sind bis zum 15. Mai $2013 \mathrm{zu}$ senden an: gsdaeb@aerztinnenbund.de. Weitere Informationen unter www.aerztinnenbund.de.

Nach einer Mitteilung des Deutschen Ärztinnenbundes e.V., Berlin 